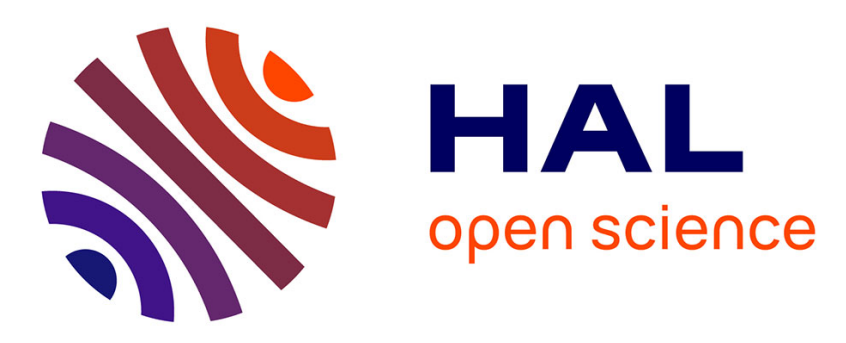

\title{
The Creation of Global Imaginaries: The Antarctic Ozone Hole and the Isoline Tradition in the Atmospheric Sciences
}

Sebastian Grevsmühl

\section{- To cite this version:}

Sebastian Grevsmühl. The Creation of Global Imaginaries: The Antarctic Ozone Hole and the Isoline Tradition in the Atmospheric Sciences. Birgit Schneider, Thomas Nocke. Image Politics of Climate Change, Transcript, pp.29-53, 2014, 978-3-8376-2610-0. hal-01519392

\author{
HAL Id: hal-01519392 \\ https://hal.science/hal-01519392
}

Submitted on 7 May 2017

HAL is a multi-disciplinary open access archive for the deposit and dissemination of scientific research documents, whether they are published or not. The documents may come from teaching and research institutions in France or abroad, or from public or private research centers.
L'archive ouverte pluridisciplinaire HAL, est destinée au dépôt et à la diffusion de documents scientifiques de niveau recherche, publiés ou non, émanant des établissements d'enseignement et de recherche français ou étrangers, des laboratoires publics ou privés.

\section{(1)(1) 8 (2)}

Distributed under a Creative Commons Attribution - NonCommercial - ShareAlikel 4.0 


\title{
The Creation of Global Imaginaries: The Antarctic Ozone Hole and the Isoline Tradition in the Atmospheric Sciences
}

\section{(in: Birgit Schneider and Thomas Nocke (eds.), Image Politics of Climate Change, Bielefeld, Transcript, 2014, p.29-53). \\ Sebastian Vincent Grevsmühl}

\begin{abstract}
This historical essay retraces from the perspective of visual and material culture how ways of analyzing and visualizing atmospheric data dramatically affect how scientific phenomena are perceived. The chapter explains in detail how NASA scientists reframed the local phenomenon of ozone depletion as a global environmental risk through their use of contour maps, displaying large quantities of global satellite data in synoptic form, coupled with the introduction of a new powerful metaphor: the "ozone hole."
\end{abstract}

\section{Introduction}

In 1990, Michael Lynch observed that the analysis of metaphors had received far more attention than had visual representations. ${ }^{1}$ Since then, research conducted in history of science and science studies has changed the scholarly landscape considerably. Beginning already in the 1980s, visual studies have received major attention from a broad variety of disciplines and today it seems that in the history of science, there is almost no major visualization technique which has attracted closer scrutiny in the form of a case study. Despite their diversity, all case studies share the claim that scientific visualizations shape scientific knowledge in a broad variety of ways. $^{2}$ Indeed, as Norton Wise has pointed out, most of the history of science could

\footnotetext{
${ }^{1}$ Lynch, "The Externalized Retina: Selection and Mathematization in the Visual Documentation of Objects in the Life Sciences," 201.

${ }^{2}$ A good place to start to get an idea of the growing field of visual studies in science studies and history of science are the following reviews: Monika Dommann, "Vom Bild zum Wissen: Eine Bestandsaufnahme wissenschaftshistorischer Bildforschung," Gesnerus 61 (2004), 77-89; Cornelius Borck, "Bild der Wissenschaft," NTM 17 (2009), 317-327; Klaus Hentschel, "Bildpraxis in historischer Perspektive: Neue Bücher zur wissenschaftlichen Bilderzeugung, -bearbeitung und -verwendung," NTM 19 (2011), 413-424.
}

In: Birgit Schneider and Thomas Nocke (eds.), Image Politics of Climate Change, Bielefeld, Transcript, 2014, pp.29-53. 
be written as a visual history in which scientific visualization would have to be integrated as "materialized arguments" instead of mere illustrations accompanying scientific discourse. ${ }^{3}$ His observation implies that scientific visualizations may indeed be useful in indicating how scientists think and interpret their findings. His call for a "materialized epistemology"4 is largely informed by two major influences which shaped the field of the history of science during the last thirty years: laboratory studies and the anthropological approach to lab-work on the one hand, and cultural history and the so-called "practical turn"5 on the other. Both fields have shown that close analysis of the actual gestures involved in scientific production, the material settings and the actual workspace play a major role in the shaping of scientific facts. Material culture is therefore one of the most promising methodologies in the analysis of scientific images and their cultural, social and historical meaning. ${ }^{6}$

This chapter will focus on a detailed study of the instrumental setting and of the gestures associated with the construction of a macroscopic geophysical phenomenon and major environmental threat widely known as the "ozone hole." Although omnipresent today, "ozone hole" visualization helped to increase public awareness of false-color imagery in combination with mappings of atmospheric processes on a global scale. I will argue that an analysis of the interaction between the visual, material and metaphorical elements may show that the metaphor of the "ozone hole" is a direct consequence of the practical and material settings of NASA's research. Although NASA scientists missed out on the opportunity to announce ozone depletion in the first place (researchers of the British Antarctic Survey (BAS) published the actual discovery of ozone depletion in 1985), the powerful metaphorical framing of the phenomenon as a "hole" in the ozone layer was nonetheless an American invention. Visual and material culture provide essential clues as to why

\footnotetext{
${ }^{3}$ Wise, "Making Visible," 75-82.

${ }^{4}$ Ibid., 81.

${ }^{5}$ The practical turn is intimately linked to the work of Ian Hacking, Nancy Cartwright, Peter Galison, David Gooding and Bruno Latour. An excellent introduction is: Lenoir, ed., Inscribing Science. Scientific Texts and the Materiality of Communication.

${ }^{6}$ Mitchell proposed in 1992 - as a corollary to Richard Rorty's "linguistic turn" - the "pictorial term," an encouragement to analyze sign systems beyond purely linguistic sign systems. An expanded version of his article was published in: Mitchell, Picture Theory. Essays on Verbal and Visual Representation, 11-34. The "iconic turn" was proposed two years later by German art historian Gottfried Boehm, reviving the idea of images in philosophical argumentation. See: Boehm, “Die Wiederkehr der Bilder,” 11-38.
}

In: Birgit Schneider and Thomas Nocke (eds.), Image Politics of Climate Change, Bielefeld, Transcript, 2014, pp.29-53. 
British researchers were referring "merely" to the phenomenon as ozone depletion, whereas the US colleagues saw a veritable hole in the sky. This case study is therefore an attempt to understand why different research communities see different things while apparently observing the same geophysical phenomenon. Finally, I would like to argue that strict micro-historical analysis has to be complemented by a broader historical inquiry into the longue durée of the "ozone hole" metaphor as well as the isoline tradition both of which proved essential in the creation of this first major global environmental threat.

\section{The British discovery of ozone depletion}

In 1985, when Joseph Farman, Brian Gardiner and Jonathan Shanklin of the British Antarctic Survey (BAS) published their findings that total stratospheric ozone values were declining considerably for the third consecutive time during the austral winter in Antarctica, their discovery was received with shock by the community of atmospheric scientists. Indeed, neither computer models, nor field or satellite observations managed to infer such a dramatic decline and none of the published chemical depletion processes could explain the alarming development. ${ }^{7}$

For NASA, since 1975 equipped by legislation with a substantial budget "to conduct a comprehensive program of research, technology and monitoring of the phenomena of the upper atmosphere," backlash. Since then, several explanations have been put forward to account for the embarrassing episode in NASA's history. ${ }^{9}$ It seems clear that Antarctic ozone research relied at the time on two distinct research traditions with expensive American big science on the one hand, and British fundamental research on the other, conducted in a conservative way with a comparatively modest budget and rather unspectacular,

\footnotetext{
${ }^{7}$ See: Stolarski, "The Antarctic Ozone Hole," 20. The discovery seemed even more spectacular in the light of institutional background and funding: the British research team was at the time a rather minor player in the field of atmospheric sciences with modest financial resources. Their findings relied on an instrument invented back in the 1920s which New Scientist columnist Fred Pearce rightly labeled “Joe Farman's old-tech triumph.” See: Pearce, "Joe Farman's Old-Tech Triumph," 46-47.

${ }^{8}$ Lambright, NASA and the Environment: The Case of Ozone Depletion, 8.

${ }^{9}$ I would like mention two commentaries in particular which contest the rumor that NASA deleted all the low ozone values below 180 Dobson units: Pukelsheim, "Robustness of Statistical Gossip and the Antarctic Ozone Hole,” 540-542; Christie, “Data Collection and the Ozone Hole: Too Much of a Good Thing?”, 99-105.
}

In: Birgit Schneider and Thomas Nocke (eds.), Image Politics of Climate Change, Bielefeld, Transcript, 2014, pp.29-53. 
almost old-fashioned instruments. However, within the Antarctic context, the conservative British approach ultimately proved highly efficient in transforming total ozone measurements into hard scientific facts.

One reason for the British success was the robustness of their data. A BAS report published in 1975 stands like no other document for the continuous British effort in documenting total ozone values observed at two research stations within the Antarctic region. ${ }^{10}$ It contains a table showing, on just a few pages, the mean total ozone values for each month of the year between 1957 and 1972. Although instrumental "friction" is not an issue in ground measurements, the values of the BAS report are nonetheless the result of an intensive effort of purification, since numerous presuppositions are attached to the measurements, such as one which states that the maximum concentration of ozone is situated at an altitude of twenty-two kilometers. Nevertheless, the British measurements certainly defined a kind of "standard" for Antarctic stratospheric ozone.

On closer observation, however, the established "standard" proved to be extremely local. Firstly, measurements in Antarctica were taken at only two stations: Halley and Argentine Islands. Secondly, those stations were not part of the global ozone network, put into place during IGY by the World Meteorological Organization (WMO) and formally institutionalized by the International Ozone Commission (IOC). ${ }^{11}$ The BAS research group profoundly mistrusted the network and the quality of the measurements, which was the main reason why they did not communicate their measurements. Even the instruments of the British Antarctic Survey were calibrated not by the international standard of the British Met Office but according to their own criteria. ${ }^{12}$ In a sense, one might say that the "standard" relied on highly local procedures and a maverick institutional culture. Yet paradoxically, the refusal to participate in the (to some eyes compromised) international network was precisely the reason for BAS' credibility. By building their own institutional and material culture, their own standards and techniques, BAS could successfully establish the credibility of the only long-term dataset of atmospheric ozone measurements on the Antarctic

\footnotetext{
${ }^{10}$ See: Farman and Hamilton, Measurements of Atmospheric Ozone at the Argentine Islands and Halley Bay.

${ }^{11}$ For a historical survey of the International Ozone Commission, see: Bojkov, The International Ozone Commission (IO3C): Its History and Activities Related to Atmospheric Ozone.

${ }^{12}$ Grevsmühl, "Interview with Jonathan Shanklin, 29 April 2008."
}

In: Birgit Schneider and Thomas Nocke (eds.), Image Politics of Climate Change, Bielefeld, Transcript, 2014, pp.29-53. 
continent. In other words, the British research group could, unlike any other, speak with legitimate authority on Antarctic ozone values.

When, at the beginning of the 1980s, total ozone values started to drop significantly during the austral spring, Joseph Farman decided to send Jonathan Shanklin to Halley with a newly calibrated instrument in order to assure that no calibration error or instrumental malfunction was biasing the measurements. Confidence could only be reestablished when both instruments, the new Dobson spectrophotometer number 123 and the old instrument number 31, worked side-byside for two weeks, producing more or less coherent measurements, allowing the measurements of the last three years to be connected to all the other total ozone values established beforehand. ${ }^{13}$ Even though several unsuccessful attempts were made to communicate with the proper satellite research group at NASA in order to obtain some sort of confirmation, the BAS group had produced, they considered, enough reliable data to submit the results to the journal Nature in late 1984. The results seemed sufficiently robust to signify a general and significant tendency. ${ }^{14}$

\section{The American context of space-based environmental monitoring}

The American space agency was confronted with completely different problems. In a brief historical reflection on the "ozone hole" discovery, Pawan Barthia, at the time a member of the Ozone Processing Team, explains very well why NASA missed out on the opportunity to announce annual ozone depletion above the Antarctic continent. ${ }^{15}$ As one of the scientists involved in writing the actual code for data reduction, Barthia explains that - as with any method of (environmental) remote

\footnotetext{
${ }^{13}$ British Antarctic Survey, Halley Bay Geophysics Report 1982.

14 Jonathan Shanklin's private archives contain two letters written in 1983 to two NASA groups asking for confirmation, but in both cases the wrong people were addressed. See also: Grevsmühl, "Interview with Jonathan Shanklin, 29 April 2008.". This also explains, at least in part, why other measurements of a Japanese research group - yet also alarming and published in 1984 - were ignored by the community. Their measurements contained a series of only eleven months and by choosing to publish in a rather unknown journal, the Japanese researchers were not able to attract sufficient attention. Their results clearly did not have the same legitimacy as those of their British colleagues. The first article mentioning stratospheric ozone depletion over Antarctica was published in 1984: Chubachi, "Preliminary Result of Ozone Observations at Syowa Station from February 1982 to January 1983," 13-19.

${ }^{15}$ See: Bhartia, "Role of Satellite Measurements in the Discovery of Stratospheric Ozone Depletion," 183-189.
}

In: Birgit Schneider and Thomas Nocke (eds.), Image Politics of Climate Change, Bielefeld, Transcript, 2014, pp.29-53. 
sensing - a great number of presuppositions had to be introduced, a necessity inherent to the method employed. Indeed, from a purely mathematical perspective, it is impossible to resolve the "problem of inverse observation" without introducing $a$ priori information. ${ }^{16}$ For the satellite Nimbus 7, Carlton L. Mateer proposed in 1971 the use of a set of standard atmospheric ozone profiles allowing calculation of the total column ozone. ${ }^{17}$ Yet none of these standard profiles allowed values below 180 Dobson units, since such values had never been observed before. For NASA, that (at the time) reasonable presupposition justified the introduction of data flags which allowed, in particular, the highlighting of data which might be corrupt, namely values below 180 or above 650 Dobson units.

That decision turned out to be a crucial one, since it initiated, at the end of 1984, a detailed spatial analysis of ozone values below 180 Dobson units, which were becoming more and more numerous in the 1983 data. The analysis showed that spatial distribution of the "errors" was not arbitrary, but that all values were well within the confines of the Antarctic continent. Based on the visualization of the "doubtful" data, NASA researchers started to suspect in late 1984 that ozone values above the Antarctic continent were indeed decreasing. The result of that analysis was presented in the following summer, in 1985, by Pawan Barthia at the joint IAGA/IAMA meeting in Prague (Figure 1) only a few months after the paper of the British Antarctic Survey ozone group was published in Nature.

\section{Lessons which may be learnt from the ozone depletion discovery}

At least three lessons can be learnt from this first part of the story. First of all, the case of ozone depletion reveals a problem which is, actually, generally well known to the field of scientific observation. The Polish philosopher and physician Ludwik Fleck was one of the first scholars to describe, during the 1930s and 40s, a

${ }^{16}$ See the mathematical explanation of the statistician Rodgers: Rodgers, Inverse Methods for Atmospheric Sounding; book cited in: Bhartia, "Role of Satellite Measurements in the Discovery of Stratospheric Ozone Depletion," 184. The TOMS instrument manual also mentions that the algorithm relies on the a priori introduction of atmospheric ozone profiles: Fleig et al., User's Guide for the Total-Ozone Mapping Spectrometer (TOMS) Instrument First-Year Ozone-T Data Set.

${ }^{17}$ Carlton L. Mateer, Donald F. Heath and Arlin J. Krueger, "Estimation of Total Ozone From Satellites Measurements of Backscattered Ultraviolet Earth Radiance," 1307-1311.

In: Birgit Schneider and Thomas Nocke (eds.), Image Politics of Climate Change, Bielefeld, Transcript, 2014, pp.29-53. 
similar problem based on his first-hand experience in medical research. ${ }^{18}$ Fleck argues that "in order to see, one has to know what is essential and what is not. [...] Otherwise one looks, but one does not see, one focuses in vain on too many details but one does not perceive the totality of the figure." ${ }^{19}$ On another occasion, he points out that "one has to learn how to look, in order to see properly.",20

If we transpose this insight to the context of remote sensing, the question of "seeing properly" indeed becomes an instrumental question which is bound, by definition, to important presuppositions which guide the researcher's gaze. Yet it is precisely at the margin of what may count as credible and what has to be discarded as an instrumental artifact that new knowledge is created. Only by allowing sufficient space for the materialization of the improbable and unpredictable within the process of scientific research can new phenomena emerge. Indeed, in his influential study on experimental research, Hans-Jörg Rheinberger has identified precisely the openness of experimental systems as the principal motor for the production of "epistemic things." 21

Secondly, one may observe that both groups were confronted in very different ways by the problem of data reduction. The British team members did not have enough measurements which they could consider "reliable" to enable them to speak of a significant statistical tendency. The space community was facing almost the opposite problem: there was a vast amount of data of which an increasing part was considered "doubtful." For one group, the production of new knowledge and confidence in the data had to be established by the multiplication of measurements, whereas the other group had first to reduce and then to reclassify the data to produce new knowledge.

Thirdly, both cases reveal a complex dialectic between the local and the global as an important characteristic of environmental remote sensing. The robustness of the British data and the legitimacy of their research relied on a very particular culture of isolation: measurements were only realized at two research stations, with only one situated on the Antarctic continent, and results were neither communicated to the

\footnotetext{
${ }^{18}$ See Fleck's article, first published in 1947: Fleck, "Schauen, sehen, wissen," 147-174.

${ }^{19}$ Ibid., 148 (own translation).

${ }^{20}$ See his 1935 article: Fleck, "Über die wissenschaftliche Beobachtung und die Wahrnehmung im allgemeinen," 60 (own translation).

${ }^{21}$ See: Rheinberger, Experimentalsysteme und epistemische Dinge, 84.
}

In: Birgit Schneider and Thomas Nocke (eds.), Image Politics of Climate Change, Bielefeld, Transcript, 2014, pp.29-53. 
global ozone network, nor to the appropriate research group within the space community. Quite paradoxically, it was the isolation that accounted for the whole coherence of the British research, ultimately enabling the "doubtful" measurements to connect to an extremely solid data base. The isolation allowed, so to speak, the transformation of doubtful data into ozone values sufficiently robust to be published. However, the British discovery was at the time a highly local phenomenon.

In order to produce the global imaginary of the "ozone hole," a truly global view had to be introduced which only the satellite could deliver. The TOMS (Total Ozone Mapping Spectrometer) instrument that was used for those measurements relied fundamentally, as any satellite remote sensing device, on what earth scientists call "ground truthing." The notion calls for information gathered in the field, in order to validate the satellite image interpretation with measurements obtained from ground-based methods. In other words, one may observe an important dialectic between the local and the global: the British research team was in many ways too local, too isolated to be able to speak of a truly global phenomenon and the Americans were too global, too far away from the local context, too attached to the synoptic view in order to effectively relate the satellite data to ground-based measurements. ${ }^{22}$ However, once both cultures were united, once a recombination of important elements from both cultures had found a common ground, a veritable "hole" in the sky emerged as one of the most powerful metaphors of a new global environmental risk.

To enable the whole complexity of the "ozone hole" history to be grasped, I propose, in the following, a detailed visual analysis of the actual images mobilized in the transformation of the phenomenon of stratospheric ozone depletion into a global environmental risk.

\section{The "ozone hole" visualizations}

Figure 2 shows a typical example of an ozone depletion visualization based on satellite data obtained from NASA's TOMS instrument on Nimbus 7. This type of image largely helped, as I will show in detail, to transform ozone depletion into the

\footnotetext{
${ }^{22}$ However, one must mention the ground-based observations which were conducted at US South Pole station, although the measurements which fell into the critical time frame were unfortunately biased by an instrumental error, allowing no confirmation of the observed depletion; see: Bhartia, "Role of Satellite Measurements in the Discovery of Stratospheric Ozone Depletion,” 185.
}

In: Birgit Schneider and Thomas Nocke (eds.), Image Politics of Climate Change, Bielefeld, Transcript, 2014, pp.29-53. 
powerful metaphor of the "ozone hole." Produced in 1986 at Goddard Space Flight Center (GSFC) by the groups responsible for the scientific analysis of the satellite data (the Ozone Processing Team and the main contractor, the Systems and Applied Sciences Corporation), this type of image was widely circulated in national and international media during the second half of the $1980 \mathrm{~s} .{ }^{23}$ The first "ozone hole" animations, based on the same kind of image, were produced by former NASA employee Mark Schoeberl who coupled an automatic camera to the mapping routines which were developed under the supervision of James A. Gatlin at Goddard by the Sensor Evaluation Branch. ${ }^{24}$ The group automated what their colleague Richard Stolarski had indeed tried before by hand: the coloring-in of total ozone contour plots (see Figure 3 for a still image and Figure 4 for an example of an ordinary contour plot). ${ }^{25}$

The examples mentioned clearly show that NASA's "ozone hole" visualizations are highly complex data products. They are a bird's eye view, allowing the integration of over 140,000 discrete daily total ozone measurements into a single image. In their most common rendition, ozone visualizations unite cartography (namely the polar orthographic projection) with geophysical measurements presented in the form of contour lines. Once received at Goddard Space Flight Center, the TOMS observations gathered on board Nimbus 7 are transformed and reduced to discrete ozone values and a computer algorithm allows the visualization of the data by connecting points of equal value by a line - a line which is generally referred to not

\footnotetext{
${ }^{23}$ The earliest published "ozone hole" visualization was produced in late 1984 and presented by Pawan Bhartia as member of the Ozone Processing Team at the IAGA symposium in Prague in August 1985. It was included in the following article: Callis and Natarajan, "The Antarctic ozone minimum: Relationship to odd nitrogen, odd chlorine, the final warming, and the 11-year solar cycle," 10774. The historical context of the first ozone hole visualization was described by Bhartia, "Role of Satellite Measurements in the Discovery of Stratospheric Ozone Depletion," 183-189.

${ }^{24}$ Personal communication of Richard McPeters (13 September 2010) and Richard Stolarski (30 August 2010). The engineer James Gatlin joined NASA in 1962. He was director of the Sensor Evaluation Branch at GSFC between 1974 and 1984. In 1984, he became director of the Engineering Directorate; see: Reisin, ed., IEEE Geoscience and Remote Sensing Newsletter 121, 7.

${ }^{25}$ Personal communication of Richard Stolarski (30 August 2010). See also the statement of Richard McPeters (member of the ozone research team at NASA during the 1980) in: Christie, The Ozone Layer. A Philosophy of Science Perspective, 51. The first "ozone hole" animations are also available as an animated atlas, see: Goddard Space Flight Center, Animated Atlas of TOMS Ozone Data, 1978-1988; for a discussion of this important resource of 3440 color visualizations, see: Chesters and Krueger, “A Video Atlas of TOMS Ozone Data, 1978-88," 15641569.
}

In: Birgit Schneider and Thomas Nocke (eds.), Image Politics of Climate Change, Bielefeld, Transcript, 2014, pp.29-53. 
only as a contour line but also an isoline. Finally, the image is color-coded, allowing more convenient identification of a specific value range. The whole process may be rendered even more complex by introducing the variable of time: several images can be combined with an animation of the spatial and temporal dynamics of the "ozone hole."

That visual and material culture do indeed not only interfere in the description of the world but also have a performative function may easily be grasped when taking a closer look at the polar orthographic projection, mobilized in most cases to depict polar phenomena. For different reasons, it is considered the most convenient way to move from the sphere to the map, at least in the case of the polar regions. However, as with any other projection type, the polar orthographic projection is only one mode of representation, chosen from amongst a large panoply of cartographic products. One should certainly not consider it "a transparent opening to the world" but rather, as any form of art, "a particular human way [...] of looking at the world." ${ }^{26}$ Most importantly, the consequences of the choice of the projection type may be farreaching, especially in the political domain. Indeed, when considering the orthographic projection, it is easy to understand why territorial claims in Antarctica always take the form of a wedge. The general adoption of this particular projection type imposes in this case its own visual logic on the domain of geopolitics. ${ }^{27}$

\section{The isoline tradition in history of cartography}

One of the most striking elements of the "ozone hole" visualizations is the contour line or the isoline. Just as the projection type, it imposes a certain pictorial logic which may easily be grasped by looking at some of its historical uses. The isoline tradition first developed within the maritime context towards the end of the $18^{\text {th }}$ century, when cartographers started to include terrestrial features in contour maps. Even though some early examples date back to the $16^{\text {th }}$ century, historians generally consider Edmond Halley to be the author of the first "scientific" contour map, a map which is based on measurements taken on two maritime voyages aboard

\footnotetext{
${ }^{26}$ Brian Harley uses a citation of Blocker, see: Harley, "Deconstructing the Map," 153.

${ }^{27}$ Another quite striking example is the famous Swiss Dufour map and the numerous controversies which it attracted during the first half of the $19^{\text {th }}$ century, see: Gugerli and Speich, Topografien der Nation. Politik, kartografische Ordnung und Landschaft im 19. Jahrhundert.
}

In: Birgit Schneider and Thomas Nocke (eds.), Image Politics of Climate Change, Bielefeld, Transcript, 2014, pp.29-53. 
the Paramour. ${ }^{28}$ His 1701 map of the "variations of the compass" (Figure 5), which has been called an "isogonic" map since the $19^{\text {th }}$ century, is indeed the first surviving example of its kind, based on geophysical measurements at some 150 locations and showing contour lines of magnetic declination (angular difference between geographic and geomagnetic north) at a very important scale. ${ }^{29}$ Since the beginning of the $18^{\text {th }}$ century, nautical charts have included contour lines indicating navigational dangers and elements of submarine topography. Terrestrial topographical maps as we know them today were introduced around 1760, when Marcellin Du Caral proposed the use of contour lines on terrestrial charts. ${ }^{30}$ However, the most emblematic figure in the isoline history is without doubt Alexander von Humboldt, who invented a whole panoply of different isolines, most notably the "isotherms" in 1817, showing mean temperature at a global scale (Figure 6). Within the history of climatology, the isoline may therefore be identified as a key instrument of what Matthias Heymann has called the period of "classical climatology" which relied mainly on the calculation of mean values of a great number of meteorological variables for their spatial representation. ${ }^{31}$ In a quite masterful way, Alexander von Humboldt achieved with this simple gesture the creation of an illusion of continuous measurement which, as Birgit Schneider has shown more generally within the context of expert visualization, only partially reveals the complexity of the construction process. ${ }^{32} \mathrm{He}$ helped enormously to popularize the method, and others followed his lead and adopted it in quite diverse contexts, ranging from meteorology to statistics. As Thomas Hankins

\footnotetext{
${ }^{28}$ Robinson, Early Thematic Mapping in the History of Cartography, 211.

${ }^{29}$ See: Thrower, "Edmond Halley as a Thematic Geo-Cartographer," 652-676.

${ }^{30}$ See: Du Carla-Boniface, Expression des nivellemens; ou, Méthode nouvelle pour marquer rigoureusement sur les cartes terrestres et marines les hauteurs et les configurations du terrein, in particular the map added at the end of the book. On the historical use of the contour line by Du Carla, see: Graber, "Le nivellement. Une mesure de l'action autour de $1800, " 51$.

31 See: Heymann, “Klimakonstruktionen. Von der klassischen Klimatologie zur Klimaforschung,” 171-197. Although the isoline still plays a key role in climatology today, the context has radically change. According to Heymann it has moved from "classical climatology" through "dynamic" or "modern climatology" (mainly influenced by the Bergen school and the inclusion of meteorological knowledge) to "modern climate research" in which computers and models play the leading role.

${ }^{32}$ See: Schneider, "Climate Model Simulation Visualization From a Visual Studies Perspective," 191-192. For a more detailed discussion of Humboldt's isotherm map, see: Schneider, "Linien als Reisepfade der Erkenntnis. Alexander von Humboldts Isothermenkarte des Klimas,". David Aubin also speaks, in the case of Humboldt's isotherm map, of the erasure of singularity, see: Aubin, "The Hotel that Became an Observatory: Mount Faulhorn as Singularity, Microcosm, and Macro-Tool," 373.
}

In: Birgit Schneider and Thomas Nocke (eds.), Image Politics of Climate Change, Bielefeld, Transcript, 2014, pp.29-53. 
has shown, from 1840 onwards, one can observe a veritable isoline "craze" with the publication of "atlases that described everything imaginable by means of isomaps.",33

Probably one of the most important aspects of NASA's "ozone hole" animations is its capacity to produce "global imaginaries," like Halley, Humboldt and Gauss masterfully did. They all knew how to create visually, and on a very important scale, geophysical phenomena that nobody would or could ever see. In other words, the history of science shows that the problem which is inherently linked nowadays to climate change, namely its very "imaginability," is by no means a new question. The isoline as a graphic tool plays a crucial role in this history. Its visual power resides in its capacity to create in a very efficient way (and probably like no other visual tool) the illusion of continuous measurement. For example, British astronomer John Herschel praised in a critical note on Gauss' latest book (which had as its main subject another global imaginary: terrestrial magnetism), the capacity of the isoline to overcome visually, thanks to graphical interpolation, the restrictions of the need for "observations and real stations" by the introduction of "imaginary stations so distributed over the globe as to afford the greatest possible facility to the calculations." 34

And indeed, the history of cartography teaches us that the contour line can either largely extrapolate on the basis of comparatively few, or even invented, data points or it can integrate an enormous amount of data into very few lines. Both, and any intermediate settings, are of course possible. By definition, the contour line does not allow for differences in a relatively small data basis, such as the 150 or so observations in Edmond Halley's case (all taken at different locations all along the tracks of his two Atlantic voyages), or a truly rich dataset of 140,000 daily ozone readings as in the case of NASA's total ozone visualizations. However, this means that the contour not only creates the illusion of continuous measurement, but it also hides very effectively its own construction process, making it impossible to judge the data basis behind the visualizations. Contour lines are therefore always both an

\footnotetext{
33 Hankins, “A 'Large and Graceful Sinuosity'. John Herschel's Graphical Method,” 624. Fitzhugh Talman, director of the Weather Bureau library, published in 1915 a list of ninety different isolines used in meteorology and their first known citation. Even though his list contains several factual errors (for example the pioneer work of Heinrich W. Brandes is not mentioned), it gives an excellent idea of how the use of isolines in the geosciences expanded rapidly during the $19^{\text {th }}$ century, see: Talman, “A List of Meteorological Isograms,” 195-198.

${ }^{34}$ John Herschel quoted in: Hankins, “A 'Large and Graceful Sinuosity.' John Herschel's Graphical Method,” 624.
}

In: Birgit Schneider and Thomas Nocke (eds.), Image Politics of Climate Change, Bielefeld, Transcript, 2014, pp.29-53. 
extremely powerful and an extremely doubtful iconographical tool. The decision of NASA scientists to mobilize contour lines on an orthographic map changed how the world viewed an important atmospheric phenomenon. As I will show in more detail in the following analysis, the isoline, as very effective graphical tool, helped to transform a highly local phenomenon into a vast, dynamic feature of continental size. Finally, and maybe most importantly, the use of the isoline also shaped the ways in which public discourse reframed ozone depletion as global environmental risk. In short, to reformulate concisely my main thesis which I will now explore in more detail: British scientists "only" saw ozone depletion whereas NASA revealed a veritable hole in the sky.

\section{The Visual Construction of the "Ozone Hole"}

The decision of NASA researchers to use isolines in combination with orthographic maps modified considerably the way a relatively local scientific phenomenon - located far from the traditional contexts of interest of Northern hemisphere States - was communicated to a large public as a global environmental risk. In adopting distinct instrumental and visual practices, British researchers were "only" able to reveal depletion where their American colleagues saw a veritable "hole" in the sky. I argue that the metaphor of the "hole" can only exist in an image sense, in other words, its ocular metaphoricity relies on an iconographical construction. Holes owe, so to speak, their very existence to a clear delimitation of space, a sharp visual distinction between an inside and an outside. Using this distinction, contour lines can create holes, whereas simple plots cannot. Contour lines create shapes and delimitate space, allowing them - especially in conjunction with color - to create holes where other visualization technologies allow "only" the depiction of tendencies such as decline or depletion. This becomes obvious when one looks at the very first plot Jon Shanklin of the British Antarctic Survey drew for the famous 1985 Nature paper on Antarctic ozone depletion (Figure 7). Effective as the graph was, showing monthly mean total ozone values (including its error bars) measured with the help of a Dobson spectrophotometer at Halley station, Shanklin's depiction did not suggest any such thing as an "ozone hole." To put it in another way, the actual visualization technology employed formatted the formulation of the scientific phenomenon. From Shanklin's ozone plot, the reader quickly grasps the In: Birgit Schneider and Thomas Nocke (eds.), Image Politics of Climate Change, Bielefeld, Transcript, 2014, pp.29-53. 
sharp local decline (which was made even more effective in its final printed version in the Nature paper with the use of a considerably shorter ordinate) in total ozone values. The metaphor of the "hole" however does not seem appropriate for this type of visual rendition.

The use of color, or rather the correlation of a certain data-interval with a specific color, helped to add the effect of homogenization to the illusion of continuous measurement. The areas which are sharply delimited by the contour lines appear to be homogenous spaces of measurement, clear and distinct objects of knowledge. The rather chaotic effects of atmospheric diffusion and circulation are in this case clearly domesticated by a powerful false color visualization technology, entertaining, as JeanMichel Besnier has rightly pointed out, a surprising metaphysical relationship with modern medical imagery, most notably with fMRI and PET scan technologies. ${ }^{35}$

In consequence, it is not surprising that the first appearance of the "ozone hole" metaphor (one definitely has to speak of a metaphor since stratospheric ozone is never removed completely) may be observed in the printed press and in conjunction with the creation of the first total ozone visualizations (based on TOMS data) by NASA scientists. Don Heath, the designer of the satellite instrument that allowed these global ozone measurements (the TOMS instrument on the Nimbus 7 satellite), gave some early color-coded ozone slides to Sherwood Rowland for a speech at the University of Maryland. In preparation for his speech, Rowland suggested the "hole" metaphor to famous New York Times science writer Walter Sullivan, who had already been the chronicler of the International Geophysical Year in the Antarctic region and who ran the first story on the "hole" in the ozone layer on November 7 , 1985, using an early black-and-white total ozone contour visualization. ${ }^{36}$ As seen above, material and visual culture largely influenced Rowland's, and finally Sullivan's, metaphorical choice. The "hole" metaphor only made sense in conjunction with contour visualizations.

In scientific publications, the "ozone hole" metaphor emerged in 1986 from the very group of NASA scientists which was more or less directly involved in the

\footnotetext{
${ }^{35}$ Besnier, "De Galilée à Google Earth - Ce que cela a changé," 186.

${ }^{36}$ Personal communication of Pawan Bhartia (10 September 2010). The first press article appeared in November 1985: Walter Sullivan, "Low Ozone Level Found Above Antarctica," New York Times, November 7, 1985, B-21. For a brief historical account, see: Reiner Grundmann, Transnationale Umweltpolitik zum Schutz der Ozonschicht (New York, Frankfurt am Main: Campus Verlag, 1995), 174-177.
}

In: Birgit Schneider and Thomas Nocke (eds.), Image Politics of Climate Change, Bielefeld, Transcript, 2014, pp.29-53. 
imaging process: Mark Schoeberl, Richard Stolarski and Richard McPeters. ${ }^{37}$ Although one referee of the Stolarski paper objected to the use of the "hole" metaphor in the title of the paper, Paul Crutzen and Frank Arnold were already permitted, less than four months later, to employ in the same journal the metaphor (albeit with quotation marks) in the title of their article. ${ }^{38}$ By 1988, a large scientific consensus had formed regarding the physical and chemical causes of ozone depletion and one can observe that the "ozone hole" was finally firmly established as an adequate metaphor of global environmental risk in both spheres, in scientific and in public discourse. ${ }^{39}$ At the time of its creation, the metaphorical force of the "ozone hole" lay probably in its heuristic and dramatic value, allowing the powerful designation of an otherwise invisible environmental risk, long before scientific consensus on the ozone destruction mechanism was achieved. Despite considerable scientific uncertainty, the metaphor helped to create an alarming discourse with significant effects within the political sphere, leading finally to the signature of the Montreal Protocol in 1987. From the point of view of metaphor theory, this suggests that although it is indeed impossible - as Max Black's interactionist theory holds - to paraphrase a metaphor without destroying its cognitive core, an active metaphor nevertheless works so effectively because the metaphorical signifier may be read and understood practically in a literal way. ${ }^{40} \mathrm{~A}$ veritable hole in the sky which lets dangerous ultraviolet rays pass almost unimpeded the atmosphere was indeed a very strong image for the environmental movement and legislators alike, pointing finally at the very limits of the biosphere where local actions can provoke effects on a truly global scale.

\footnotetext{
37 “The deep minimum, or hole...," citation on p.810 in: Richard Stolarski et al., "Nimbus 7 satellite measurements of the springtime Antarctic ozone decrease," Nature, 322 (1986), 808-811.

${ }^{38}$ Paul Crutzen and Frank Arnold, "Nitric acid cloud formation in the cold Antarctic stratosphere: a major cause for the springtime 'ozone hole'," Nature, 324 (18 December 1986), 651-655.

${ }^{39}$ See also quantitative analysis in Reiner Grundmann, Transnationale Umweltpolitik zum Schutz der Ozonschicht (New York, Frankfurt am Main: Campus Verlag, 1995), 177.

40 American philosopher Donald Davidson defended the rather radical thesis that "metaphors mean what the words, in their most literal interpretation, mean, and nothing more": Davidson, "What Metaphors Mean," 31-47, here 32. This important shift from semantics to pragmatics can however be useful in explaining the actual use of the "ozone hole" metaphor. For Max Black’s interactionist theory, see: Black, "More about Metaphor," 19-41.
}

In: Birgit Schneider and Thomas Nocke (eds.), Image Politics of Climate Change, Bielefeld, Transcript, 2014, pp.29-53. 


\section{Conclusion}

The combined visual and material approach I employed in the above analysis indicates in detail how a historical cartographic tool could be put effectively to use in the construction of an influential global imaginary, showing considerable effects well beyond scientific discourse, most notably in the political sphere. In particular, I argued that the isoline shaped the metaphorical choice of the "ozone hole," transforming thereby a local depletion phenomenon into a global environmental risk. With the help of TOMS ozone visualizations the scientific community, policy makers, and the broader public received both: synoptic visualizations and a powerful metaphor. Together, they could constitute and frame the "ozone hole" as an emblem of a fragile planet, a symbol of global environmental catastrophe as well as an icon of the global environment. It is precisely in this tradition in which contemporary icons of climate change, as for example the so-called red planet, try to inscribe themselves. ${ }^{41}$

And only against this specific historical backdrop is it possible to understand the political responses which led to the signature of the Montreal Protocol and its successive amendments. Scientific consensus was only established after the signature of the Montreal Protocol in 1987, most notably following in situ NASA measurements conducted in the Antarctic vortex during the austral spring of 1987. That mission, known as the Airborne Antarctic Ozone Experiment (AAOE), allowed for the discovery of the "smoking gun," the decisive visual proof of the "culpability" of chlorofluorocarbons (CFC) in ozone destruction, by showing a strong anticorrelation between the chemically active parts of the CFCs and the overall ozone concentration. $^{42}$

Several explanations have been put forward to account for this at first glance unusual situation. For example, within the political sciences, Peter Haas argued that in the case of ozone depletion, political action, largely informed by the precautionary principle, is a direct consequence of the formation and action of a strong "epistemic

\footnotetext{
${ }^{41}$ On the making and function of climate change icons such as the red planet, see: Schneider, "Climate Model Simulation Visualization From a Visual Studies Perspective," 185-193.

42 AAOE and the "smoking gun" are discussed in all the important books on ozone depletion, most notably in: Parson, Protecting the Ozone Layer, 150-153, as well as in: Christie, The Ozone Layer. A Philosophy of Science Perspective, 60-65.
}

In: Birgit Schneider and Thomas Nocke (eds.), Image Politics of Climate Change, Bielefeld, Transcript, 2014, pp.29-53. 
community." 43 His notion refers to a group of professionals who share a certain number of values and practices concerning the ways in which to treat environmental problems, as well as an interpretive framework to judge them by. According to Haas, shortly after Farman's article appeared in press in 1985, ozone experts, politicians, and representatives of NGO's and scientific institutions came together to form an "epistemic community," leading to the signature of the Montreal Protocol, even in the absence of a general scientific consensus on the actual causes of annual ozone depletion.

My approach showed that it is indeed possible and legitimate to extend that explanation by accentuating the dynamics of visual and material culture which constituted the foundation of scientific practice, of the knowledge of the "epistemic community" and of the discourses mobilized. As I have shown, ozone research within the Antarctic context goes well back to the mid- $20^{\text {th }}$ century and the International Geophysical Year, preceding largely contemporary environmental preoccupations. In the case of stratospheric ozone, the British Antarctic Survey initiated its own values, practices, norms, and standards, assuring thereby a certain degree of coherence which gave their ozone data set an important legitimacy and robustness. Combined with the synoptic satellite views of NASA, this "infrastructural" (Paul Edwards) knowledge formed an important basis for all the main political actions that followed. Hence, material and visual culture contributed together, metaphorically and visually, to the creation of a powerful global imaginary, sending to a vast public the message of urgency and planetary crisis.

Today, in the aftermath of Climategate, the common contesting of expert graphics and climate models calls for a reproduction of the ozone "success story" within the climate change regime are clearly understandable. Most explanations which try to account for the fact that a similar adoption process has not worked for climate change, are to my mind, gross oversimplifications as they systematically

\footnotetext{
${ }^{43}$ See: Haas, Saving the Mediterranean: The Politics of International Environmental Cooperation. See also his articles which discuss the ozone case in detail: Haas, "Obtaining International Environmental Protection through Epistemic Consensus," 347-364; Haas, "Banning Chlorofluorocarbons: Epistemic Community Efforts to Protect Stratospheric Ozone," 187-224.
}

In: Birgit Schneider and Thomas Nocke (eds.), Image Politics of Climate Change, Bielefeld, Transcript, 2014, pp.29-53. 
underestimate the complexity of the ozone issue. ${ }^{44}$ However, and this essay hopefully did not fail to make this point, engaging in longer historical dynamics may help reestablish the historical richness as well as the historical complexity of our objects of study. Indeed, in science studies, in environmental history, and in the history of science we are only just starting to understand the complexity of global environmental issues.

\section{Index of Figures}

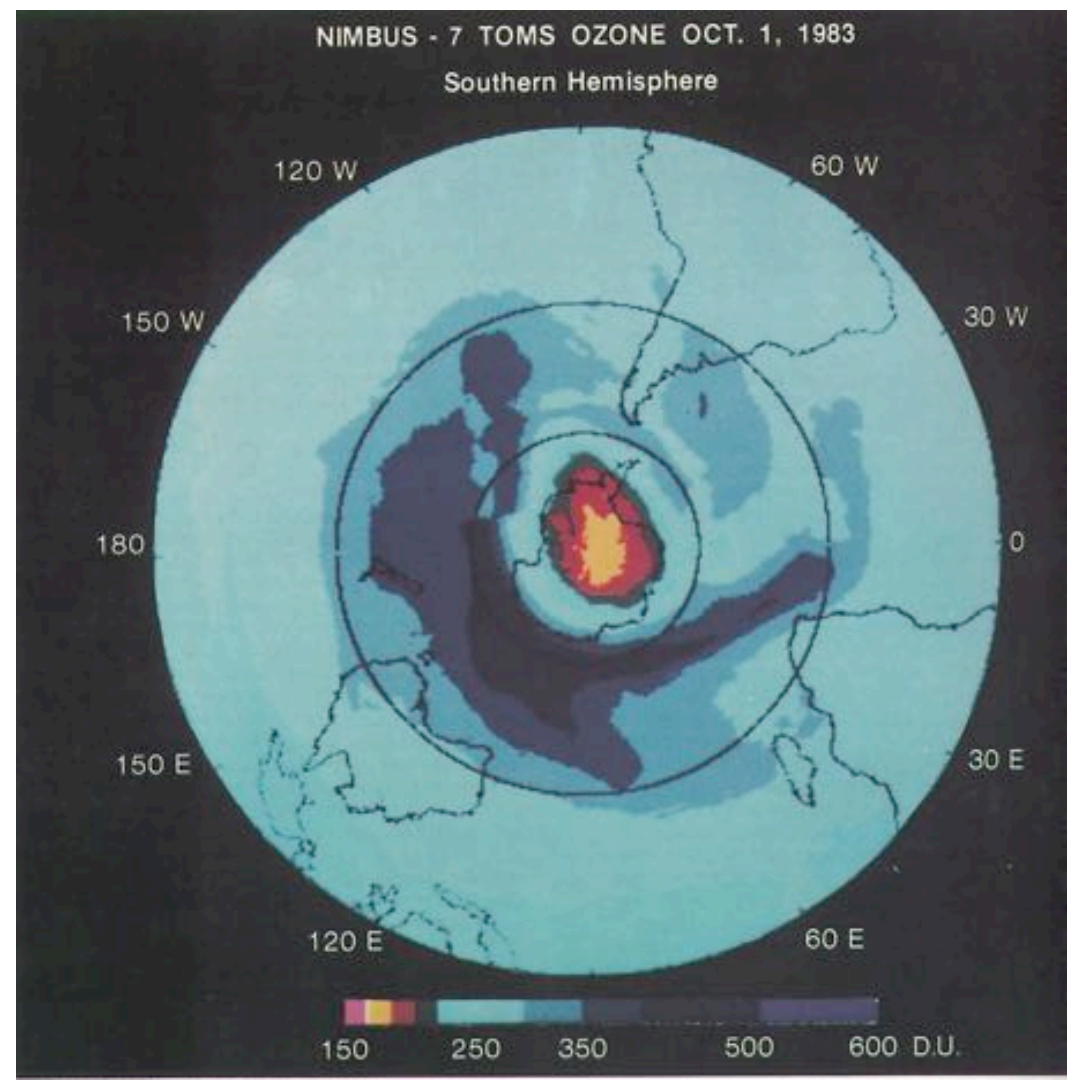

Figure 1: Satellite map of total ozone above the Antarctic region for October 1, 1983. In order to produce this map, the standard ozone profiles were arbitrarily extrapolated to include values below 180 Dobson units (Source: NASA image).

\footnotetext{
${ }^{44}$ Although I agree with Ungar on many points, his paper on climate change and the ozone hole is a typical example of an underestimation of the complexity of the ozone case, see: Ungar, "Knowledge, Ignorance, and the Popular Culture: Climate Change versus the Ozone Hole,” 297-312.
}

In: Birgit Schneider and Thomas Nocke (eds.), Image Politics of Climate Change, Bielefeld, Transcript, 2014, pp.29-53. 


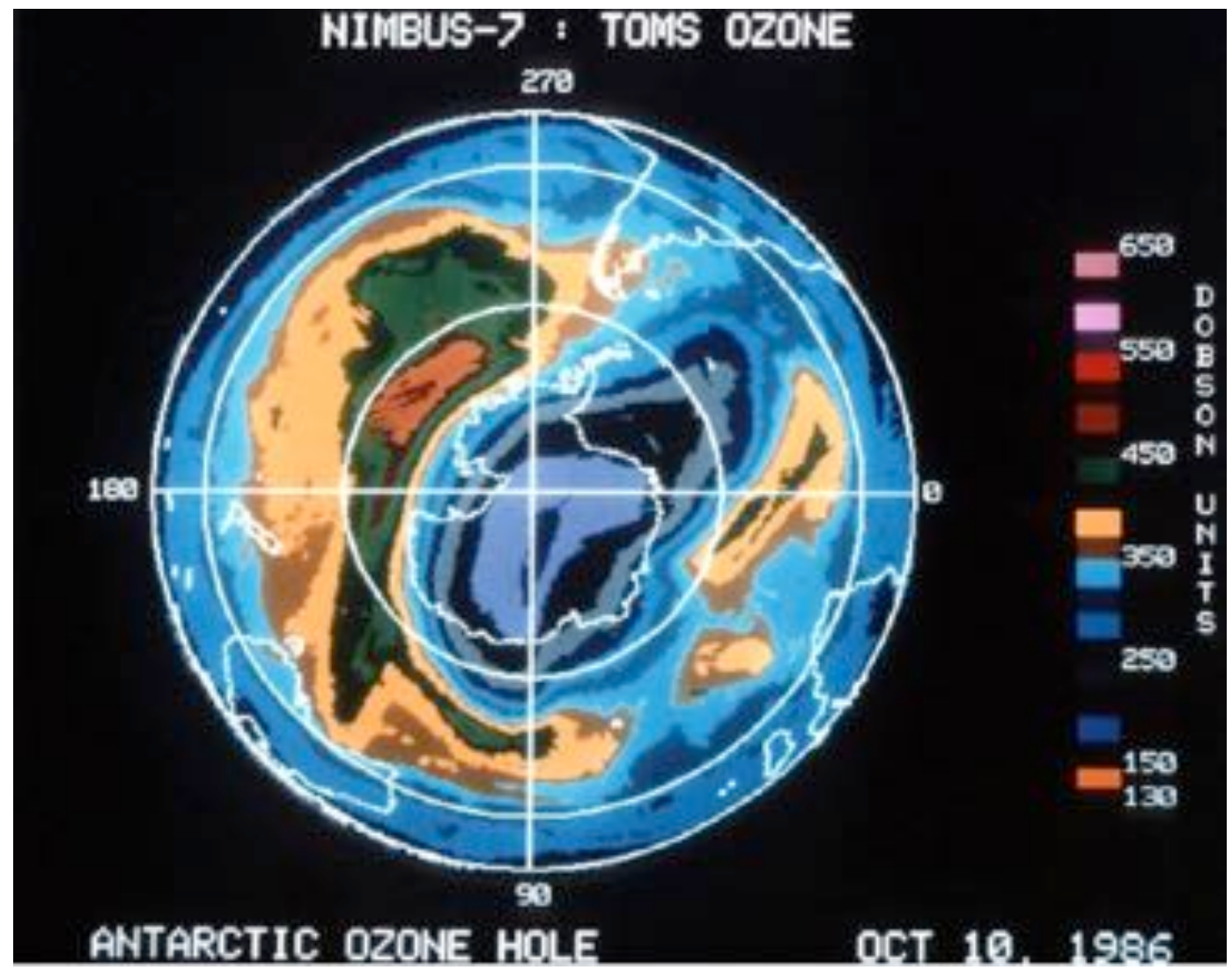

Figure 2: Satellite map showing total ozone in the Southern hemisphere in polar orthographic projection for October 10, 1986. At the center, in a darker shade of blue, the so-called "ozone hole" is depicted (defined as values below 220 Dobson units). Measurements were taken with the TOMS instrument aboard NASA's Nimbus 7 satellite (Source: NASA image 86-HC-289).

In: Birgit Schneider and Thomas Nocke (eds.), Image Politics of Climate Change, Bielefeld, Transcript, 2014, pp.29-53. 


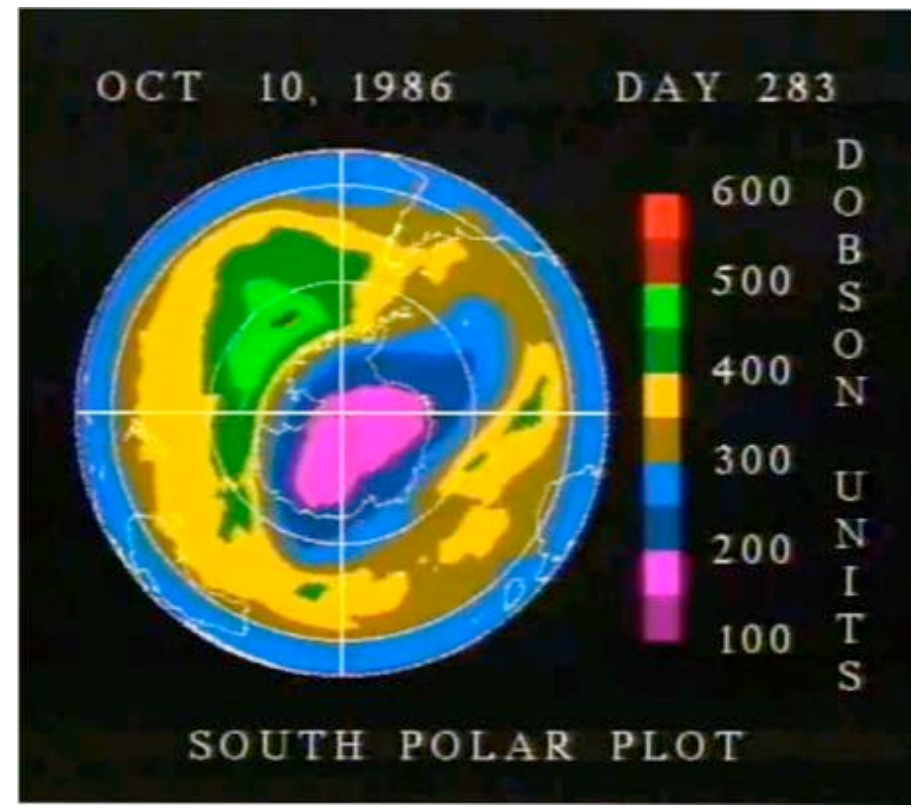

Figure 3: Still image of the animated ozone atlas produced by STX, showing a total ozone map for October 10, 1986 as in the previous figure, but with an altered color code. The "ozone hole" shows up as a violet patch at the center of the image (Source: Goddard Space Flight Center, Animated Atlas of TOMS Ozone Data, 1978-1988, VHS (NTSC), 40 min., NSSDC Photo Lab, 1989).

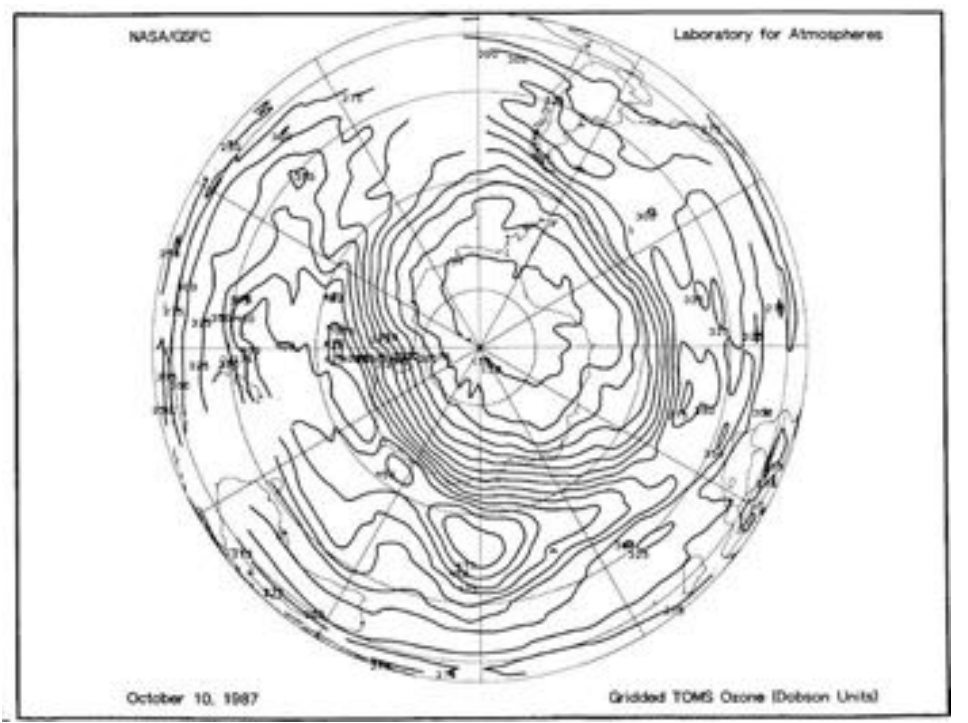

Figure 4: For comparison, ozone contour plot of total ozone over Antarctica one year later, on October 10, 1987 with values dropping as low as 150 Dobson units (Source: Arlin J. Krueger, et al., The 1987 Airborne Antarctic Ozone Experiment: The Nimbus7 TOMS Data Atlas, Washington, D.C.: NASA, 1988, p.164).

In: Birgit Schneider and Thomas Nocke (eds.), Image Politics of Climate Change, Bielefeld, Transcript, 2014, pp.29-53. 


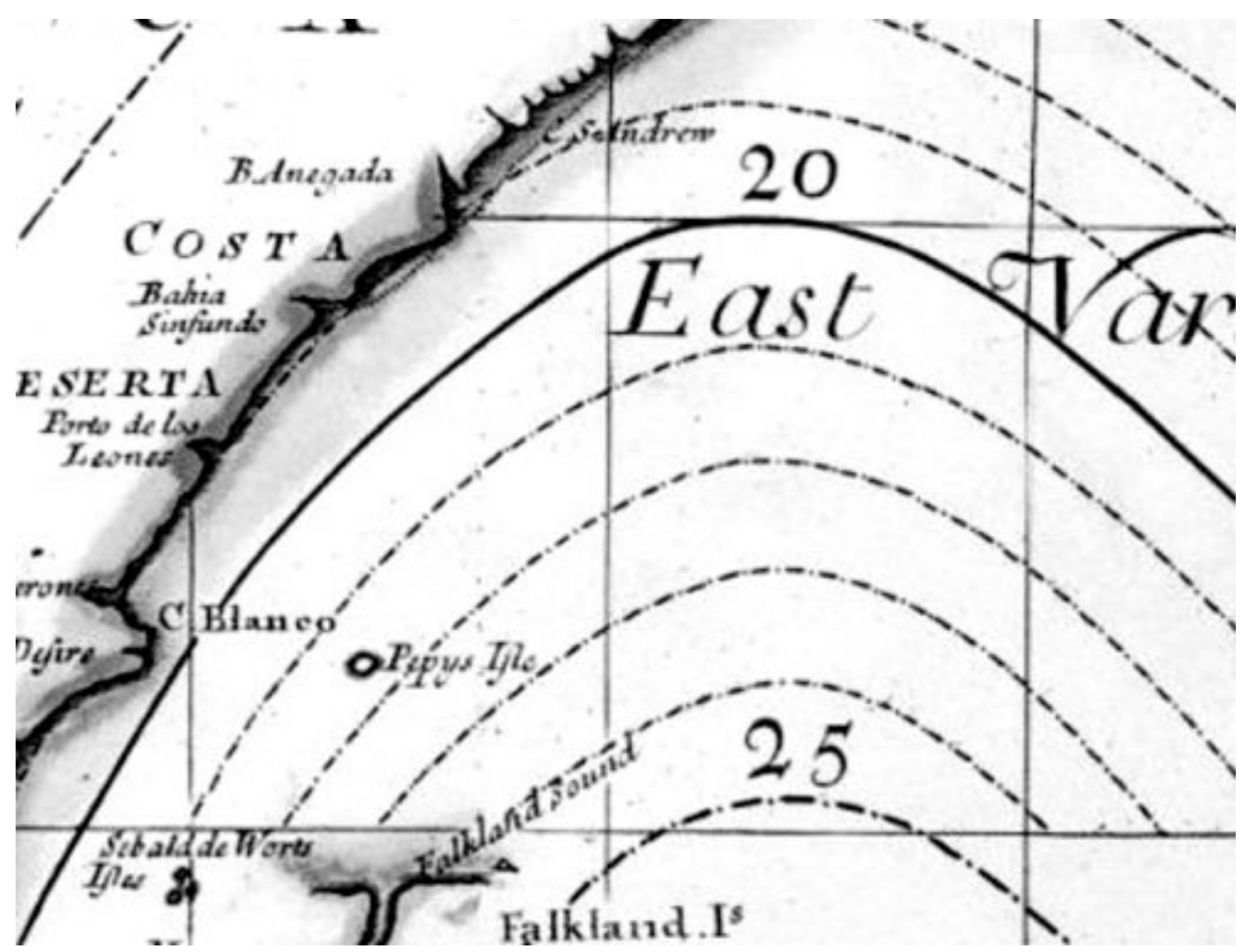

Figure 5: Detail of a so-called "isogonic" map produced in 1701 by Edmond Halley and believed to be first data-based contour map showing lines of equal magnetic declination (Friendly, M. \& Denis, D. J. (2001). Milestones in the history of thematic cartography, statistical graphics, and data visualization. Web document, http://www.datavis.ca/milestones/).

In: Birgit Schneider and Thomas Nocke (eds.), Image Politics of Climate Change, Bielefeld, Transcript, 2014, pp.29-53. 


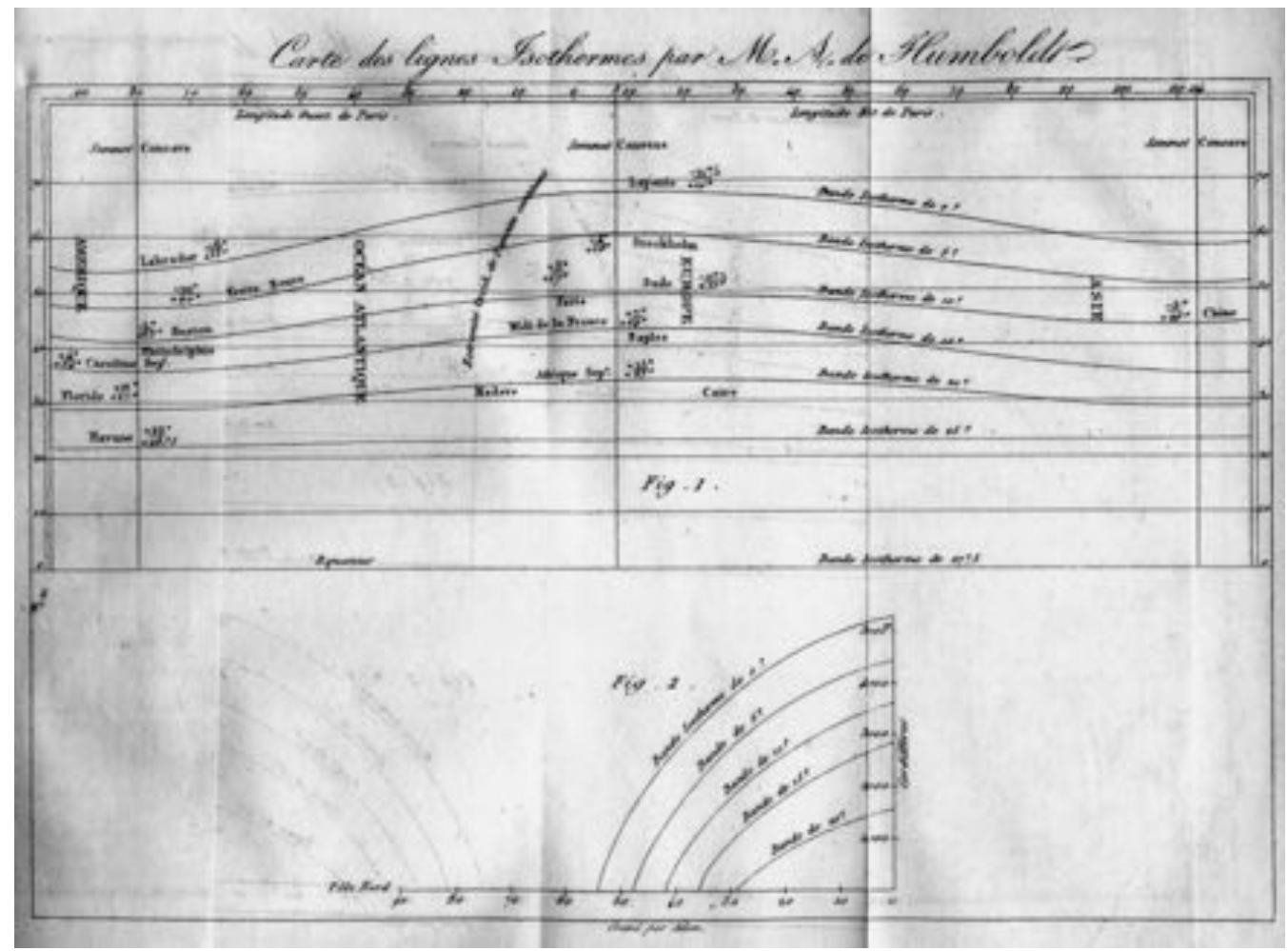

Figure 6: First graph of "isotherms" (upper part of image) showing mean temperature for the Northern hemisphere spanning from America to China. Alexander von Humboldt, "Carte des lignes Isothermes.” Paris: V.H. Perronneau, 1817.

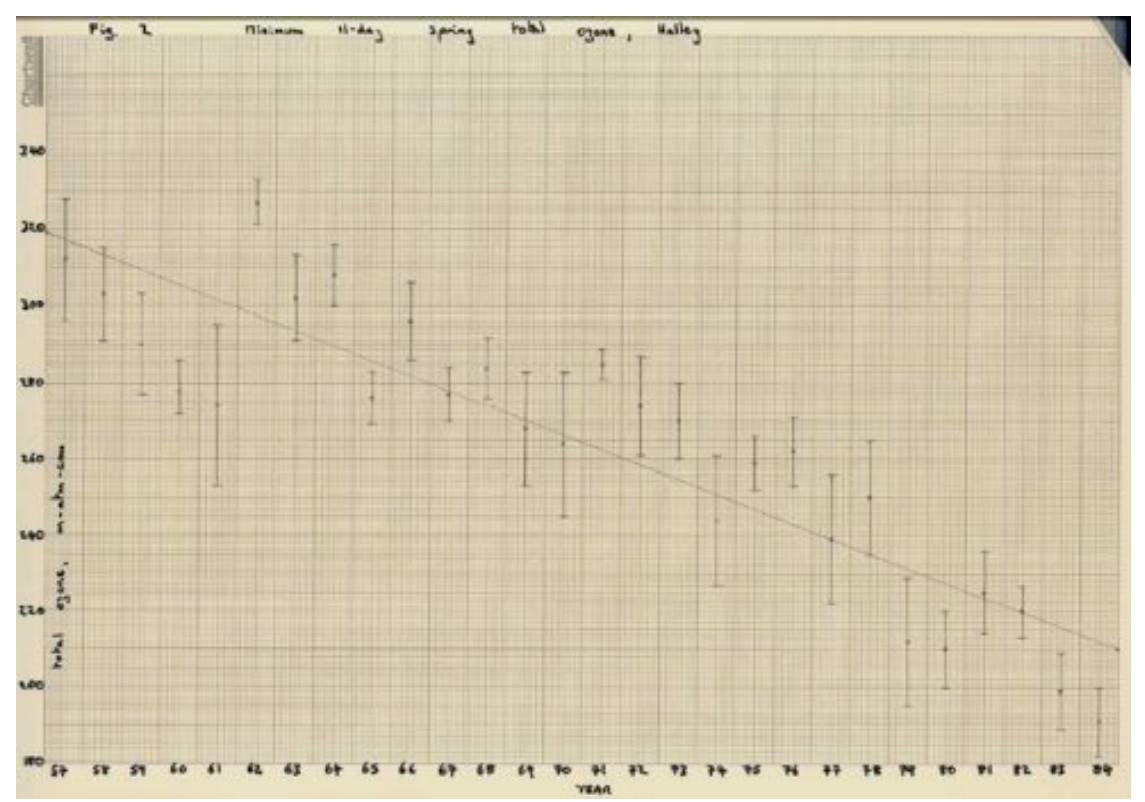

Figure 7: Jon Shanklin's original "Minimum 11-day Spring Total Ozone” plot for the famous 1985 Nature paper, covering 1957-1984, revealing dramatic ozone decline above Halley, Antarctica (author's collection).

In: Birgit Schneider and Thomas Nocke (eds.), Image Politics of Climate Change, Bielefeld, Transcript, 2014, pp.29-53. 


\section{Bibliography}

Aubin, David. "The Hotel that Became an Observatory: Mount Faulhorn as Singularity, Microcosm, and Macro-Tool.” Science in Context 22 (2009), 365-386.

Besnier, Jean-Michel. "De Galilée à Google Earth - Ce que cela a changé." In Objectifs Terre. La Révolution des Satellites, edited by Catherine Cornu, 175-191. Paris: Le Pommier, Cité des Sciences et de l'Industrie, 2009.

Bhartia, Pawan K. "Role of Satellite Measurements in the Discovery of Stratospheric Ozone Depletion." In Twenty Years of Ozone Decline, edited by Christos Zerefos, 183-189. Dordrecht: Springer, 2009.

Black, Max. "More about Metaphor." In Metaphor and Thought, $2^{\text {nd }}$ ed., edited by Andrew Ortony, 19-41. Cambridge: Cambridge University Press, 1993.

Boehm, Gottfried. "Die Wiederkehr der Bilder." In Was ist ein Bild?, edited by Gottfried Boehm, 11-38. München: Wilhelm Fink, 1996.

Bojkov, Rumen D. The International Ozone Commission (IO3C): Its History and Activities Related to Atmospheric Ozone. Athens: Academy of Athens, 2010.

Borck, Cornelius. "Bild der Wissenschaft.” NTM 17 (2009), 317-327.

British Antarctic Survey. Halley Bay Geophysics Report 1982, AD6/2Z/1982/01, Archives of the British Antarctic Survey, Cambridge, UK.

Callis, Linwood, and Murali Natarajan. "The Antarctic Ozone Minimum: Relationship to Odd Nitrogen, Odd Chlorine, the Final Warming, and the 11-year Solar Cycle.” Journal of Geophysical Research 91 (1986), 10771-10796.

Chesters, Dennis, and Arlin J. Krueger. “A Video Atlas of TOMS Ozone Data, 197888.” Bulletin of the American Meteorological Society 70 (1989), 1564-1569.

In: Birgit Schneider and Thomas Nocke (eds.), Image Politics of Climate Change, Bielefeld, Transcript, 2014, pp.29-53. 
Christie, Maureen. "Data Collection and the Ozone Hole: Too Much of a Good Thing?" History of Meteorology 1 (2004), 99-105.

Christie, Maureen. The Ozone Layer: A Philosophy of Science Perspective. Cambridge: Cambridge University Press, 2001.

Chubachi, Shigeru. "Preliminary Result of Ozone Observations at Syowa Station from February 1982 to January 1983.” In Memoirs of National Institute of Polar Research, special issue no. 34, 13-19. Proceedings of the Sixth Symposium on Polar Meteorology and Glaciology, Tokyo: National Institute of Polar Research, 1984.

Crutzen, Paul, and Frank Arnold. "Nitric Acid Cloud Formation in the Cold Antarctic Stratosphere: a Major Cause for the Springtime 'Ozone Hole'." Nature 324 (18 December 1986), 651-655.

Davidson, Donald. “What Metaphors Mean.” Critical Inquiry 5 (1978), 31-47.

Dommann, Monika. "Vom Bild zum Wissen: eine Bestandsaufnahme wissenschaftshistorischer Bildforschung." Gesnerus 61 (2004), 77-89.

Du Carla-Boniface, Marcellin. Expression des nivellemens; ou, Méthode nouvelle pour marquer rigoureusement sur les cartes terrestres et marines les hauteurs et les configurations du terrein. Paris: L. Cellot, 1782.

Farman, Joseph C., Brian G. Gardiner and Jonathan D. Shanklin. "Large Losses of Total Ozone in Antarctica Reveal Seasonal CIOx/NOx Interaction." Nature 315 (1985), 207-210.

Farman, Joseph C., and Richard A. Hamilton. Measurements of Atmospheric Ozone at the Argentine Islands and Halley Bay, 1957-72. British Antarctic Survey Scientific Report no. 90, Cambridge: British Antarctic Survey, 1975.

In: Birgit Schneider and Thomas Nocke (eds.), Image Politics of Climate Change, Bielefeld, Transcript, 2014, pp.29-53. 
Fleck, Ludwik. "Schauen, sehen, wissen.” In Ludwik Fleck, Erfahrung und Tatsache. Gesammelte Aufsätze, 147-174. Frankfurt am Main: Suhrkamp, 1983.

Fleck, Ludwik. "Über die wissenschaftliche Beobachtung und die Wahrnehmung im allgemeinen.” In Ludwik Fleck, Erfahrung und Tatsache. Gesammelte Aufsätze, 5983. Frankfurt am Main: Suhrkamp, 1983.

Fleig Albert J. et al. User's Guide for the Total-Ozone Mapping Spectrometer (TOMS) Instrument First-Year Ozone-T Data Set, Washington, D.C.: NASA, 1982.

Goddard Space Flight Center. Animated Atlas of TOMS Ozone Data, 1978-1988, VHS (NTSC), 40 min., NSSDC Photo Lab, 1989.

Graber, Frédéric. "Le nivellement. Une mesure de l'action autour de 1800," Histoire \& Mesure 21 (2006), 29-54.

Grevsmühl, Sebastian. Interview with Jonathan Shanklin, 29 April 2008, British Antarctic Survey, Cambridge.

Grundmann, Reiner. Transnationale Umweltpolitik zum Schutz der Ozonschicht. New York, Frankfurt am Main: Campus Verlag, 1995.

Gugerli, David, and Daniel Speich. Topografien der Nation. Politik, kartografische Ordnung und Landschaft im 19. Jahrhundert. Zürich: Chronos Verlag, 2002.

Haas, Peter M. Saving the Mediterranean: The Politics of International Environmental Cooperation. New York: Columbia University Press, 1990.

Haas, Peter M. "Obtaining International Environmental Protection through Epistemic Consensus.” Millennium 19 (1990), 347-364.

Haas, Peter M. "Banning Chlorofluorocarbons: Epistemic Community Efforts to Protect Stratospheric Ozone.” International Organization 46 (1992), 187-224.

In: Birgit Schneider and Thomas Nocke (eds.), Image Politics of Climate Change, Bielefeld, Transcript, 2014, pp.29-53. 
Hankins, Thomas L. “A 'Large and Graceful Sinuosity.' John Herschel's Graphical Method." Isis 97 (2006), 605-633:624.

Harley, J. Brian. "Deconstructing the Map." In The New Nature of Maps: Essays in the History of Cartography, edited by Paul Laxton, 149-168. Baltimore: Johns Hopkins University Press, 2001.

Hentschel, Klaus. "Bildpraxis in historischer Perspektive: Neue Bücher zur wissenschaftlichen Bilderzeugung, -bearbeitung und -verwendung.” NTM 19 (2011), 413-424.

Heymann, Matthias. "Klimakonstruktionen. Von der klassischen Klimatologie zur Klimaforschung.” NTM 17 (2009), 171-197.

Lambright, Henry. NASA and the Environment: The Case of Ozone Depletion. Washington, D.C.: NASA History Division, 2005.

Lenoir, Timothy. Inscribing Science. Scientific Texts and the Materiality of Communication. Stanford: Stanford University Press, 1998.

Lynch, Michael. "The Externalized Retina: Selection and Mathematization in the Visual Documentation of Objects in the Life Sciences.” Human Studies 11 (1988), 201-234.

Mateer, Carlton L., Donald F. Heath and Arlin J. Krueger. "Estimation of Total Ozone From Satellites Measurements of Backscattered Ultraviolet Earth Radiance.” Journal of Atmospheric Science 28 (1971), 1307-1311.

Mitchell, William J. T. Picture Theory. Essays on Verbal and Visual Representation. Chicago: University of Chicago Press, 1994.

Parson, Edward A. Protecting the Ozone Layer. New York: Oxford University Press, 2003.

In: Birgit Schneider and Thomas Nocke (eds.), Image Politics of Climate Change, Bielefeld, Transcript, 2014, pp.29-53. 
Pearce, Fred. “Joe Farman’s Old-Tech Triumph.” New Scientist 199 (2008), 46-47.

Pukelsheim, Friedrich. "Robustness of Statistical Gossip and the Antarctic Ozone Hole.” Institute of Mathematical Statistics Bulletin 19 (1990), 540-542.

Reisin, Steven C., editor, IEEE Geoscience and Remote Sensing Newsletter. New York: Geoscience and Remote Sensing Society, 121 (2001).

Rheinberger, Hans-Jörg. Experimentalsysteme und epistemische Dinge. Göttingen: Wallstein Verlag, 2001.

Robinson, Arthur H. Early Thematic Mapping in the History of Cartography. Chicago: Chicago University Press, 1982.

Rodgers, Clive D. Inverse Methods for Atmospheric Sounding. New York: World Scientific Publishing, 2000.

Schneider, Birgit. "Climate Model Simulation Visualization From a Visual Studies Perspective." WIREs Climate Change 3 (2012), 185-193.

Schneider, Birgit. "Linien als Reisepfade der Erkenntnis. Alexander von Humboldts Isothermenkarte des Klimas.” In KartenWissen. Territoriale Räume zwischen Bild und Diagramm, edited by Stephan Günzel and Lars Nowak, 173-197. Wiesbaden: Ludwig Reichert Verlag, 2011.

Stolarski, Richard, et al. "Nimbus 7 Satellite Measurements of the Springtime Antarctic Ozone Decrease.” Nature 322 (1986), 808-811.

Stolarski, Richard. “The Antarctic Ozone Hole.” Scientific American 258 (1988), 2026.

Sullivan, Walter. "Low Ozone Level Found Above Antarctica." New York Times, November 7, 1985, B-21.

In: Birgit Schneider and Thomas Nocke (eds.), Image Politics of Climate Change, Bielefeld, Transcript, 2014, pp.29-53. 
Talman, Fitzhugh. “A List of Meteorological Isograms.” Monthly Weather Review 43 (1915), 195-198.

Thrower, Norman J. W. "Edmond Halley as a Thematic Geo-Cartographer." Annals of the Association of American Geographers 59 (1969), 652-676.

Ungar, Sheldon. "Knowledge, Ignorance, and the Popular Culture: Climate Change versus the Ozone Hole.” Public Understanding of Science 9 (2000), 297-312.

Wise, Norton. “Making Visible.” Isis 97 (2006), 75-82.

Personal communication of Richard McPeters (13 September 2010).

Personal communication of Richard Stolarski (30 August 2010).

Personal communication of Pawan Bhartia (10 September 2010).

In: Birgit Schneider and Thomas Nocke (eds.), Image Politics of Climate Change, Bielefeld, Transcript, 2014, pp.29-53. 